\title{
SEBARAN TOTAL SUSPENDED SOLID (TSS) PERMUKAAN DI PERAIRAN DESA WAWATU, KECAMATAN MORAMO UTARA KABUPATEN KONAWE SELATAN
}

\section{Distribution of Total Suspended Solid Surfaces In Wawatu Village, North Moramo District, South Konawe Regency}

\author{
Faya Masria Nurfatimah ${ }^{1}$, La Ode Alirman $\mathrm{Afu}^{2}$, A. Ginong Pratikino ${ }^{3}$ \\ ${ }^{1}$ Mahasiswa Jurusan Ilmu Kelautan, \\ Fakultas Perikanan dan Ilmu Kelautan, Universitas Halu Oleo. \\ Jl. H.E.A Mokodompit Kampus Hijau Bumi Tridharma Anduonohu Kendari 93232, Telp/Fax: (0401) 3193782 \\ ${ }^{2}$ Surel: alirmanotsudari@ymail.com \\ ${ }^{3}$ Surel: asringinong@gmail.com
}

\begin{abstract}
Abstrak
Peningkatan Total Suspended Solid (TSS) akan mempengaruhi kualitas perairan sehingga tidak mampu untuk mendukung kehidupan oranisme perairan tersebut. Perairan Desa Wawatu merupakan wilayah pesisir yang menjadi muara baik sungai besar maupun sungai kecil serta aktivitas pembangunan pesisir yang cukup padat. Dampak yang ditimbulkan adalah meningkatnya kekeruhan perairan yang dapat memicu peningkatan kadar TSS akibat penambahan pasokan material-material dari daratan. Oleh karena itu perlu adanya penelitian tentang tingkat kandungan TSS perairan di Perairan Desa Wawatu yang nantinya dapat dijadikan sebagai bahan informasi untuk pengelolaan wilayah pesisir yang lebih baik dan bijaksana. Penelitian ini dilaksanakan pada bulan Januari-Februari 2019 dengan menggunakan data TSS insitu 10 sampel yang dianggap mewakili perairan Desa Wawatu. Pengambilan sampel air dilakukan pada saat air laut menjelang surut kemudian dianalisis menggunakan metode gravimetri. Hasil yang diperoleh kadar TSS di perairan Desa Wawatu berkisar antara 136-224 mg/l. Kadar TSS tertinggi sebesar $224 \mathrm{mg} / \mathrm{l}$ dan kadar TSS terendah yaitu $136 \mathrm{mg} / \mathrm{l}$. Kadar TSS tersebut telah melebihi baku mutu TSS perairan berdasarkan Keputusan Menteri Lingkungan Hidup No. 51 tahun 2004.
\end{abstract}

Kata kunci: Desa Wawatu, Total Suspended Solid

\begin{abstract}
The increase in Total Suspended Solid (TSS) will affect the quality of the water so that it is unable to support the lives of these aquatic organisms. The waters of Wawatu Village are coastal areas that are the estuary of large rivers and small rivers as well as fairly dense coastal development activities. The impact is an increase in turbidity of the waters which can trigger an increase in TSS levels due to the addition of supply of materials from the mainland. Therefor, there is a need for research on the level of TSS content in the waters of Wawatu Village which can later be used as information material for better an wise coastal area management. This research was conducted in January-February 2019 using TSS data in 10 samples which were considered to reprensent the waters of Wawatu Village. The taking of water samples is carried out when the seawater before receding is then analyzed using the gravimetric method. The result obtained from TSS levels in the waters of Wawatu Village ranged from 136-224 mg/l. The highest TSS level was $224 \mathrm{mg} / \mathrm{l}$ and the lowest TSS level was $136 \mathrm{mg} / \mathrm{l}$. TSS levels have exceeded TSS water quality standards based on Decree of Minister of Environment No. 51 of 2004.
\end{abstract}

Key words: Wawatu Village, Total Suspended Solid

\section{Pendahuluan}

Perairan laut merupakan salah satu perairan yang dinamis, khususnya di daerah pesisir yang menjadi daerah peralihan antara daratan dan lautan. Masuknya material daratan dapat menimbulkan kekeruhan suatu perairan. Kekeruhan perairan erat hubungannya dengan zat atau bahan tersuspensi dalam air yang terdiri dari pasir halus, liat yang merupakan bahan tersuspensi melayang-layang dalam air atau dapat berupa mikroorganisme seperti bakteri, alga dan sebagainya. Kekeruhan memang disebabkan karena adanya zat tersuspensi dalam air, namum karena zat yang terbentuk dan berat jenisnya berbeda-beda maka kekeruhan tidak selalu sebanding dengan kadar zat tersuspensi (Purba et al., 2018).

Padatan Total Suspended Solid (TSS) merupakan bahan-bahan tersuspensi yang (diameter $>1 \mu \mathrm{m}$ ) yang bertahan pada saringan mili pore dengan diameter pori-pori $0,45 \mu \mathrm{m}$ yang terdiri dari lumpur dan pasir halus serta jasad-jasad renik, yang terutama disebabkan oleh kikisan tanah atau erosi tanah yang 
terbawa ke badan air (Effendi, 2003). Padatan tersuspensi yang tinggi akan akan mempengaruhi biota air didalamnya. Pengukuran sedimen tersuspensi secara insitu menjadi salah satu alternatif untuk mengetahui kondisi lingkungan berdasarkan pada parameter fisika (Susanti et al., 2010).

Perairan Desa Wawatu merupakan daerah yang padat akan aktivitas manusia. Selain itu perairan Desa Wawatu menjadi muara sungai yang berpengaruh terhadap keseimbangan ekosistem yang ada disekitar perairan. Semua material dari aktivitas tersebut masuk ke dalam perairan dan mengendap di dasar perairan. Dampak yang ditimbulkan adalah penambahan pasokan material-material yang cukup merugikan bagi wilayah pesisir. Oleh karena itu perlu adanya penelitian tentang tingkat kandungan TSS perairan di Perairan Desa Wawatu yang nantinya dapat dijadikan sebagai bahan informasi untuk pengelolaan wilayah pesisir yang lebih baik dan bijaksana.

\section{Bahan dan Metode}

Penelitian ini dilaksanakan pada bulan Januari-Februari 2019 yang meliputi tahap pengambilan data lapangan dan analisis sampel. Pengambilan data lapangan dilakukan di Perairan Desa Wawatu, Kecamatan Moramo Utara, Kabupaten Konawe Selatan, Sulawesi Tenggara.
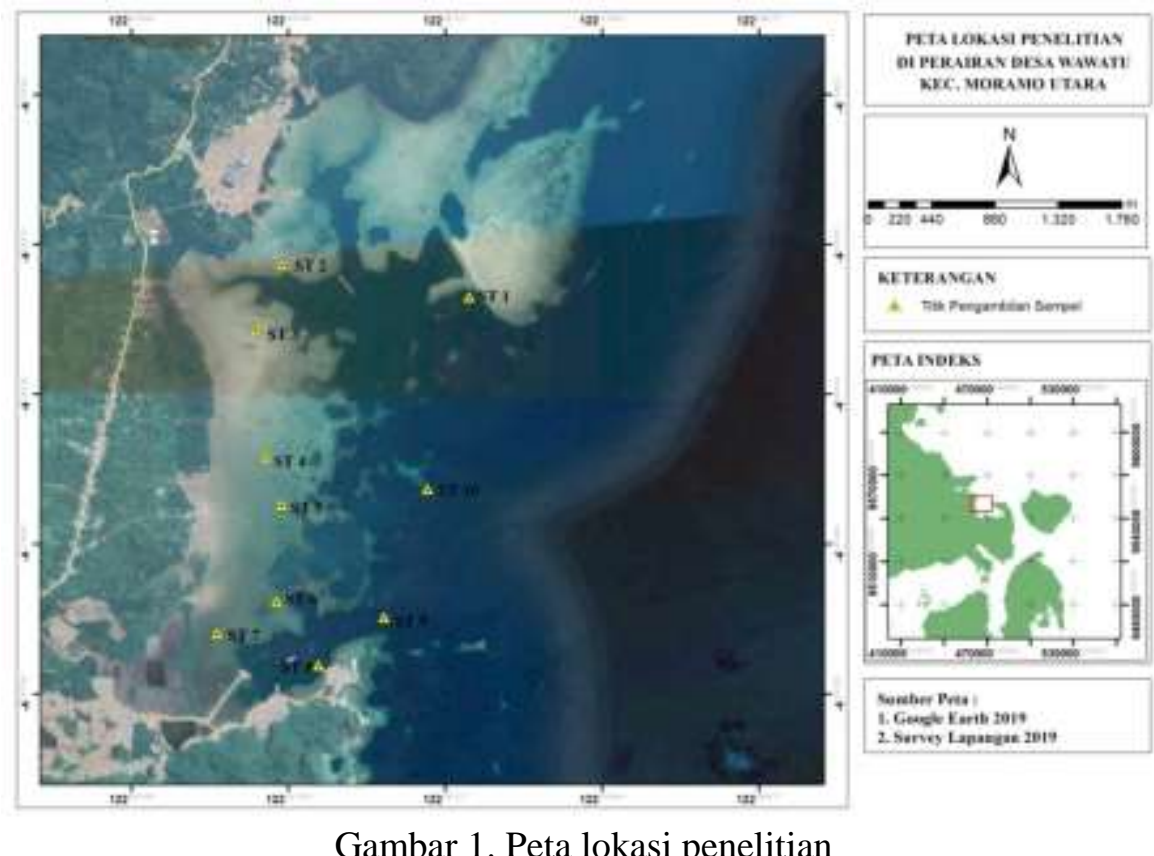

Tabel 1. Alat dan bahan yang digunakan beserta kegunaannya

\begin{tabular}{|c|c|c|}
\hline No. & Alat dan Bahan & Kegunaan \\
\hline 1. & $\begin{array}{ll}\text { Alat } \\
- & \text { GPSmap } 76 C S x \\
- & \text { Botol sampel } \\
- & \text { Kertas saring whatman } 0,45 \\
& \mu \mathrm{m} \\
- & \text { Oven } \\
- & \text { Corong kaca } \\
- & \text { Gelas ukur } 100 \mathrm{ml} \\
- & \text { Timbangan analitik } \\
- & \text { Perahu } \\
- & \text { Kamera } \\
- & \text { Alat tulis } \\
- & \text { Coolbox }\end{array}$ & $\begin{array}{l}\text { Penentuan titik koordinat } \\
\text { Tempat air sampel TSS } \\
\text { Penyaring sampel TSS } \\
\text { Pengering sampel TSS } \\
\text { Alat bantu penyaring sampel } \\
\text { Alat ukur sampel air yang disaring } \\
\text { Penimbang sampel TSS } \\
\text { Transportasi untuk mengambil sampel air } \\
\text { Dokumentasi kegiatan } \\
\text { Menandai sampel air } \\
\text { Tempat menyimpan sampet TSS }\end{array}$ \\
\hline 2. & $\begin{array}{l}\text { Bahan } \\
-\quad \text { Air laut }\end{array}$ & Objek pengamata \\
\hline
\end{tabular}




\section{Prosedur Penelitian}

Survey pendahuluan dilakukan untuk mengetahui kondisi lokasi penelitian secara menyeluruh dan bertujuan untuk menentukan stasiun pengambilan sampel yang dianggap dapat mewakili kondisi keberadaan sebaran TSS di Perairan Desa Wawatu.

Pengambilan data penelitian meliputi dua bagian yaitu data primer dan data sekunder. Data primer, data yang diambil dari lapangan berupa data TSS yang diambil di 10 titik lokasi penelitian yang dapat mewakili Perairan Desa Wawatu bagian dalam berdasarkan sebaran TSS.

\section{Analisis Data}

Menurut Satriadi dan Widada (2004), bahwa analisis sampel sedimen tersuspensi (TSS) dianalisis menggunakan metode Gravimetri. Partikel besar yang mengapung pada sampel dipisahkan terlebih dahulu, kemudian botol sampel dikocok agar air sampel dan partikel-partikel teraduk rata dan terhindar dari penempelan partikel padatan pada dinding botol sampel, lalu kertas saring whatman ditimbang dengan timbangan analitik sebelum proses penyaringan pada sampel, berat kertas saring dicatat, kemudian kertas saring diletakkan di atas gelas ukur, sebelumnya kertas saring dibasahi dengan sedikit air suling guna memineralisasi kertas saring sebelum menuangkan air sampel, lalu perlahan-lahan tuangkan air sampel.

Setelah padatan tersuspensi tersaring pada kertas saring whatman, masukan saring yang berisi padatan tersuspensi tersebut ke dalam oven pada pada suhu $103^{\circ} \mathrm{C}-105^{\circ} \mathrm{C}$ selama $1 \mathrm{jam}$. Setelah proses pengeringan di dalam oven selesai, sampel didinginkan dalam desikator, lalu kertas saring ditimbang dengan timbangan analitik hingga memperoleh berat yang konstan atau sampai perubahan berat lebih kecil dari $4 \%$ terhadap penimbangan sebelumnya atau lebih kecil dari $0,5 \mathrm{mg}$.

Menurut Peraturan Pemerintah No. 82 Tahun 2001 nilai padatan tersuspensi dapat diperoleh dengan persamaan sebagai berikut :

$T S S=\frac{(\text { Wt }- \text { Wo }) \times 1000}{\text { volume sampel awal }(\mathrm{ml})}$

Dimana: $\mathrm{Wt}=$ Berat kering sampel dan residu sesudah pemanasan $(\mathrm{mg})$; Wo $=$ Berat kering kosong (mg).

\section{Hasil dan Pembahasan}

Berdasarkan hasil analisis yang telah dilakukan, konsentrasi TSS di Perairan Desa Wawatu dapat dilihat pada Gambar 2. Gambar 2 menunkukkan bahwa, kadar TSS berada pada kisaran nilai 136-224 mg/l. Konsentrasi TSS pada air laut di Perairan Desa Wawatu pada semua titik pengambilan sampel telah melebihi baku mutu yang telah ditetapkan oleh Keputusan Menteri Lingkungan Hidup No 51 tahun 2004 sebesar $80 \mathrm{mg} / \mathrm{l}$ untuk wisata bahari dan mangrove, $20 \mathrm{mg} / \mathrm{l}$ untuk lamun dan karang. Hal ini menunjukkan banyaknya bahan padatan yang berasal dari daratan masuk ke perairan sehingga mengganggu keseimbangan ekosistem perairan tersebut.

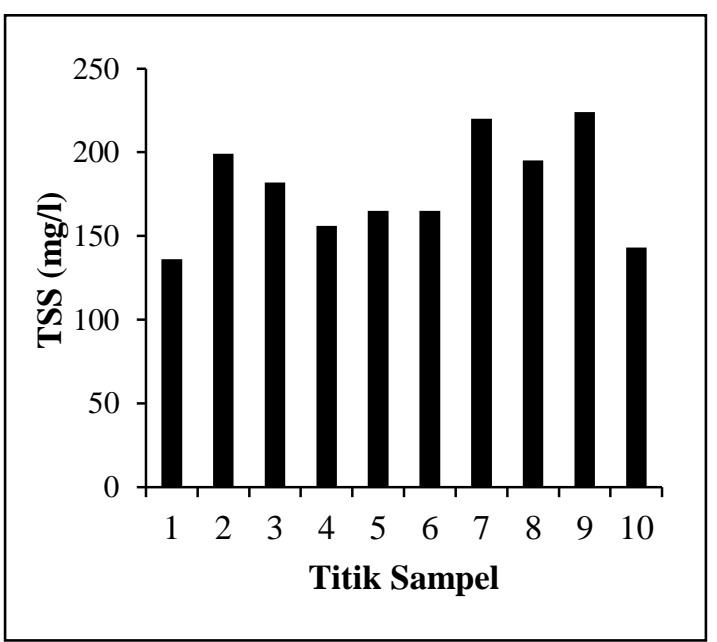

Gambar 2. Konsentrasi TSS di Perairan Desa Wawatu

Kadar TSS tertinggi terdapat pada lokasi sampling ST9 (kawasan tambang batu moramo) dan ST7 (kawasan pelabuhan) berturut-turut sebesar $224 \mathrm{mg} / \mathrm{l}$ dan $220 \mathrm{mg} / \mathrm{l}$. Hal ini menunjukkan bahwa kawasan pertambangan dan pelabuhan menyumbang bahan padatan ke perairan. Beberapa aktivitas pengerukan dan reklamasi di wilayah pesisir juga dapat menjadi penyumbang tingginya kadar TSS di perairan. Kadar TSS terendah terdapat pada lokasi sampling ST1 yaitu sebesar $136 \mathrm{mg} / \mathrm{l}$. Kadar TSS pada lokasi ini juga cukup tinggi karena sudah melebihi baku mutu perairan. Hal ini disebabkan karena lokasi ini merupakan kawasan yang jauh dari daratan namun daerah ini masih cukup berdekatan dengan pelabuhan PLTU. 
Tingginya kadar TSS bersumber dari semua zat padat (pasir, lumpur dan tanah liat) atau partikel-partikel yang tersuspensi dalam air dan dapat berupa komponen hidup (biotik) seperti fitoplankton, zooplankton, bakteri, fungi ataupun komponen mati (abiotik) seperti detritus dan partikel-partikel anorganik. Zat padat tersuspensi merupakan tempat berlangsungnya reaksi kimia yang heterogen dan berfungsi sebagai bahan pembentuk endapan paling awal dan dapat menghalangi kemampuan produksi zat organik disuatu perairan (Tarigan dan Edward, 2003). TSS yang tinggi pun dapat menimbulkan dampak lain seperti disebutkan oleh Rifardi (2008) bahwa nilai konsentrasi padatan tersuspensi total yang tinggi dapat menurunkan aktivitas fotosintesa tumbuhan laut baik yang mikro maupun makro sehingga oksigen yang dilepaskan tumbuhan menjadi berkurang dan mengakibatkan ikanikan menjadi mati. Sehingga apabila konsentrasi TSS yang ada pada badan sungai terus bertambah dan mengalir ke lautan lepas dalam jangka waku yang lama dapat menurunkan kualitas perairan.

\section{Simpulan}

Berdasarkan hasil penelitian yang telah dilakukan dapat disimpulkan bahwa kadar TSS di perairan Desa Wawatu berkisar antara 136-224 mg/l. Kadar TSS tersebut sudah melebihi baku mutu TSS berdasarkan Keputusan Menteri Lingkungan Hidup No. 51 tahun 2004.

\section{Daftar Pustaka}

Effendi, H. 2003. Telaah Kualitas Air Bagi Pengelolaan Sumber Daya dan Lingkungan Perairan. Yogyakarta: Kanisius. 98 hal.

Menteri Negara Lingkungan Hidup. 2004. Surat Keputusan Menteri Negara Lingkungan Hidup Nomor : 51 Tahun 2004 tentang Baku Mutu Air Laut untuk Biota Laut. Jakarta.

Purba, R.T., Mubarak dan Galib, M. 2018. Sebaran Total Suspended Solid (TSS) di Kawasan Muara Sungai Kampar Kabupaten Pelalawan Provinsi Riau. Jurnal Perikanan dan Kelautan. Vol. 23(1): 21-30.

Rifardi. 2008. Distribution of sediment, Benthic Foraminifera and Mercury in the South Yatsushiro Sea, Kyushu,
Japan. Journal of Coastal Development. Research Institute Diponegoro University. Vol. 11(3): 104-122.

Satriadi, A. dan Widada, S. 2004. Distribusi Muatan Padatan Tersuspensi di Muara Sungai Bodri, Kabupaten Kendal. Jurnal Ilmu Kelautan. Vol. 9(2): 101107.

Susiati, H.E., Kusratmoko dan A. Poniman. 2010. Pola Sebaran Sedimen Tersuspensi Melalu Pendekatan Penginderaan Jauh di Perairan Pesisir Semenanjung Muria-Jepara. Jurnal Teknologi Pengelolaan Limbah. Vol. 13(1).

Tarigan, M.S. dan Edward. 2003. Kandungan Total Zat Padat Tersuspensi (Total Suspended Solid) di Perairan Raha Sulawesi Tenggara. Jurnal Bidang Dinamika Laut. LIPI. Vol. 7(3): 109119. 